\title{
HDlive and 4D Ultrasound in the Assessment of Twin Pregnancy
}

\author{
${ }^{1}$ Toshiyuki Hata, ${ }^{2}$ Kenji Kanenishi, ${ }^{3}$ Uiko Hanaoka, ${ }^{4}$ Mohamed Ahmed Mostafa AboEllail, ${ }^{5}$ Genzo Marumo
}

\begin{abstract}
Four-dimensional (4D) ultrasound facilitates the evaluation of fetal development, inter-human contact, and intra-pair stimulation in twin pregnancies. HDlive is a new surfacerendering mode, which uses an adjustable light source that facilitates the ability to create lighting and shadowing effects, thereby increasing depth perception. In this article, we discuss recent topics regarding twin fetal development in the first and second trimesters of pregnancy, inter-twin contacts in the first trimester, the Kurjak antenatal neurodevelopmental test (KANET) in twin fetuses, and prediction of twin temperament using HDlive and 4D ultrasound. HDlive and 4D ultrasound may become an important modalities in future research on twin fetal neurobehavioral development, and assist in the evaluation of inter-twin relationships and differences in twin fetal temperament.
\end{abstract}

Keywords: Four-dimensional ultrasound, HDlive, Twin pregnancy, Fetal development, Inter-twin contact, KANET, Twin temperament.

How to cite this article: Hata T, Kanenishi K, Hanaoka U, AboEllail MAM, Marumo G. HDlive and 4D Ultrasound in the Assessment of Twin Pregnancy. Donald School J Ultrasound Obstet Gynecol 2015;9(1):51-60.

Source of support: Nil

Conflict of interest: None

\section{INTRODUCTION}

Twin fetuses are thought to be an experiment of nature, offering a unique opportunity to explore social behavior before birth. ${ }^{1}$ Twin fetuses are naturally exposed to sensory stimulations from the co-twin fetus, and may be regarded as an ideal model to investigate the onset of reactions toward touch in utero. ${ }^{2}$ The occurrence of intra-pair stimulation in twin fetuses may provide

\footnotetext{
${ }^{1}$ Professor and Chairman, ${ }^{2}$ Associate Professor

${ }^{3}$ Senior Assistant Professor, ${ }^{4}$ Research Fellow, ${ }^{5}$ President

${ }^{1-4}$ Department of Perinatology and Gynecology, Kagawa University Graduate School of Medicine, Japan

${ }^{5}$ Department of Obstetrics and Gynecology, Marumo Ladies Clinic, Japan

Corresponding Author: Toshiyuki Hata, Professor and Chairman, Department of Perinatology and Gynecology, Kagawa University Graduate School of Medicine, 1750-1 Ikenobe, Miki Kagawa 761-0793, Japan, Phone: +81-(0)87-891-2174, e-mail: toshi28@med.kagawa-u.ac.jp
}

important clues regarding the functioning of tactile and proprioceptive sensitivity, which cannot be evaluated with an intact singleton fetus. ${ }^{3}$

Hata et al ${ }^{4}$ were the first to assess three-dimensional (3D) ultrasound images of various types of inter-twin contact and intra-pair stimulation in twin fetuses in all three trimesters of pregnancy. Only with the introduction of four-dimensional (4D) ultrasound has the full range of twin fetal developments and inter-twin contacts been investigated in real time. ${ }^{1,5-13}$ HDlive is a new $3 \mathrm{D} / 4 \mathrm{D}$ surface-rendering mode, which uses an adjustable light source that facilitates the ability to create lighting and shadowing effects, thereby increasing depth perception. ${ }^{14}$ This technique provides such extraordinarily realistic imaging of normal and abnormal embryos and fetuses that it is almost impossible to differentiate between actual photographs and HDlive images. ${ }^{14-23}$

In the present review article, we discuss recent topics regarding twin fetal development in the first and second trimesters of pregnancy, inter-twin contacts and intra-pair stimulations in the first trimester, the Kurjak antenatal neurodevelopmental test (KANET) in twin fetuses, and prediction of twin temperament using HDlive and 4D ultrasound.

\section{SINGLETON FETAL DEVELOPMENT IN THE FIRST TRIMESTER}

In normal pregnancy, morphological and anatomical developments of the embryo and fetus can be clearly shown employing HDlive in the first trimester of pregnancy (Figs 1 to 5). HDlive shows the embryo as a solid, comma-shaped structure adjacent to the yolk sac in the gestational sac at 6 weeks' gestation (Fig. 1). ${ }^{17}$ HDlive facilitates the anatomically realistic visualization of all structures of the embryo or fetus, umbilical cord, midgut herniation, amniotic sac, and yolk sac at 7 to 11 weeks of gestation (Figs 2 and 3). ${ }^{16,23}$ The fetal facial anatomy can be recognized at 12 to 13 weeks of gestation (Figs 4 and 5). ${ }^{23}$

\section{TWIN FETAL DEVELOPMENT IN THE FIRST TRIMESTER}

In dichorionic diamniotic (DD) twins, each twin fetus in each gestational sac with a thick dividing membrane is evident at 7 to 8 weeks of gestation (Figs 6 and 7). HDlive demonstrates two embryos in two separate amniotic sacs 


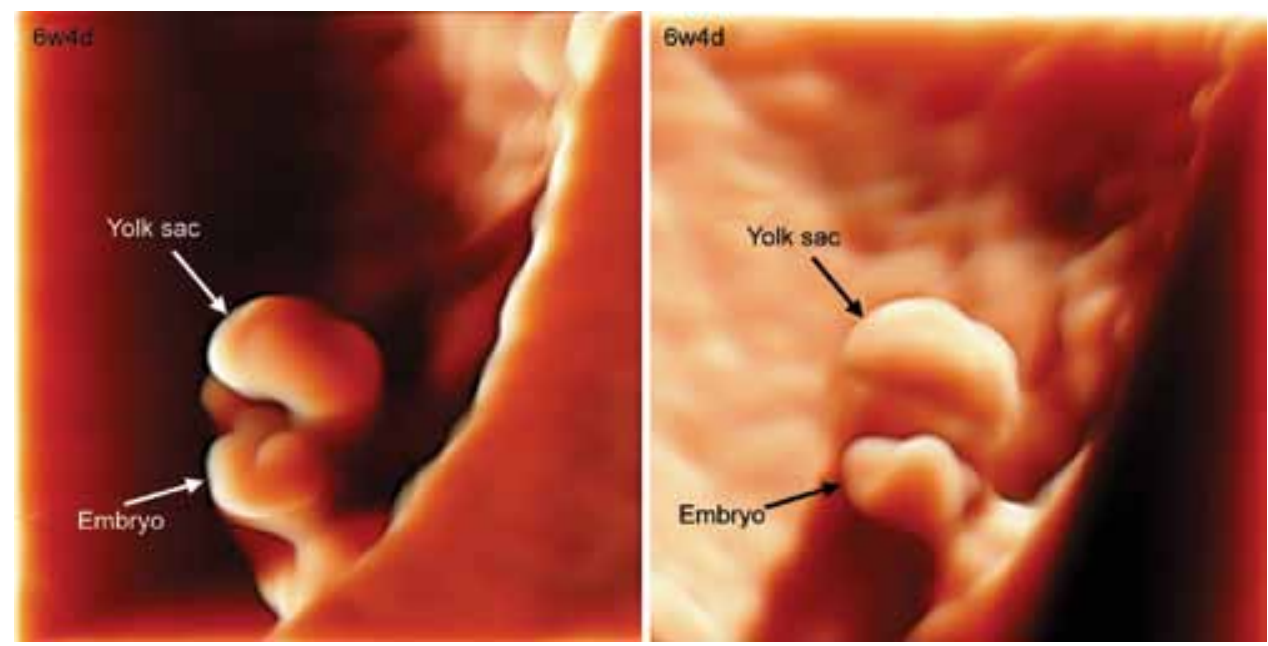

Fig. 1: HDlive images of an embryo and yolk sac at 6 weeks and 4 days of gestation. The crown-rump length is $3.3 \mathrm{~mm}$ (Courtesy: Reprinted with permission from Hata T, et al) ${ }^{17}$
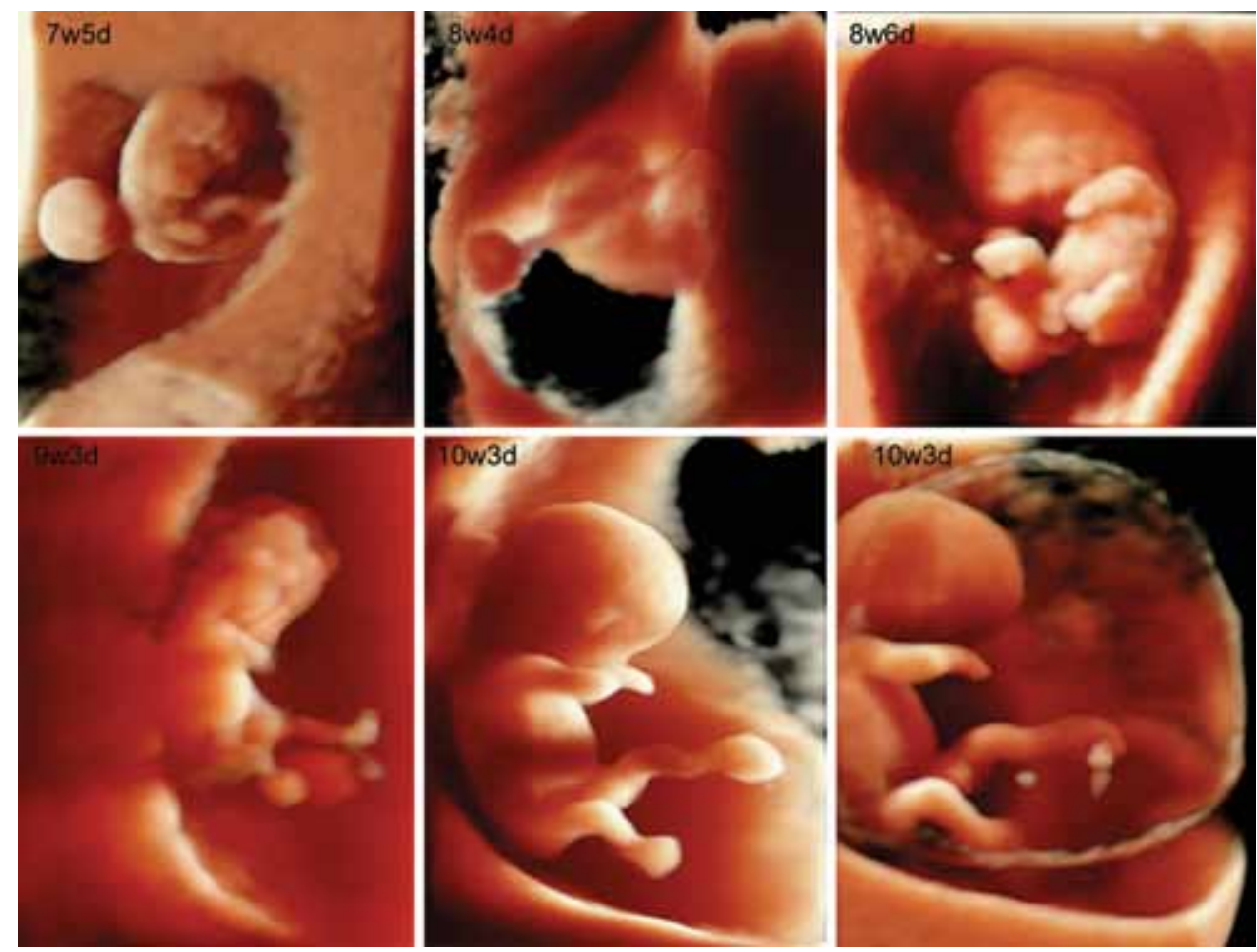

Fig. 2: HDlive images of normal embryonic morphological development at 7 to 10 weeks of gestation (Courtesy: Reprinted with permission from Hata T, et al) ${ }^{16}$

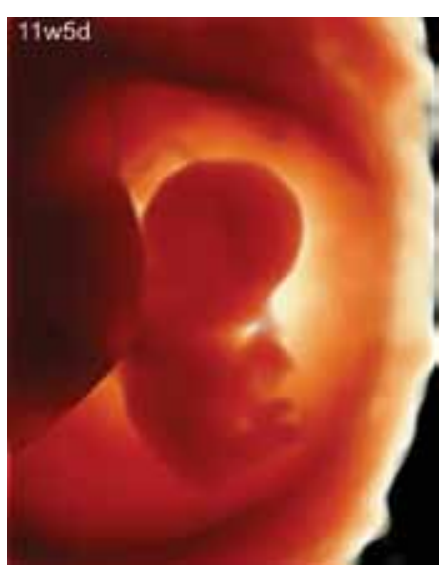

Fig. 3: HDlive image of a fetus at 11 weeks and 5 days of gestation (Courtesy: Reprinted with permission from Hata $\mathrm{T}$, et al) $)^{23}$
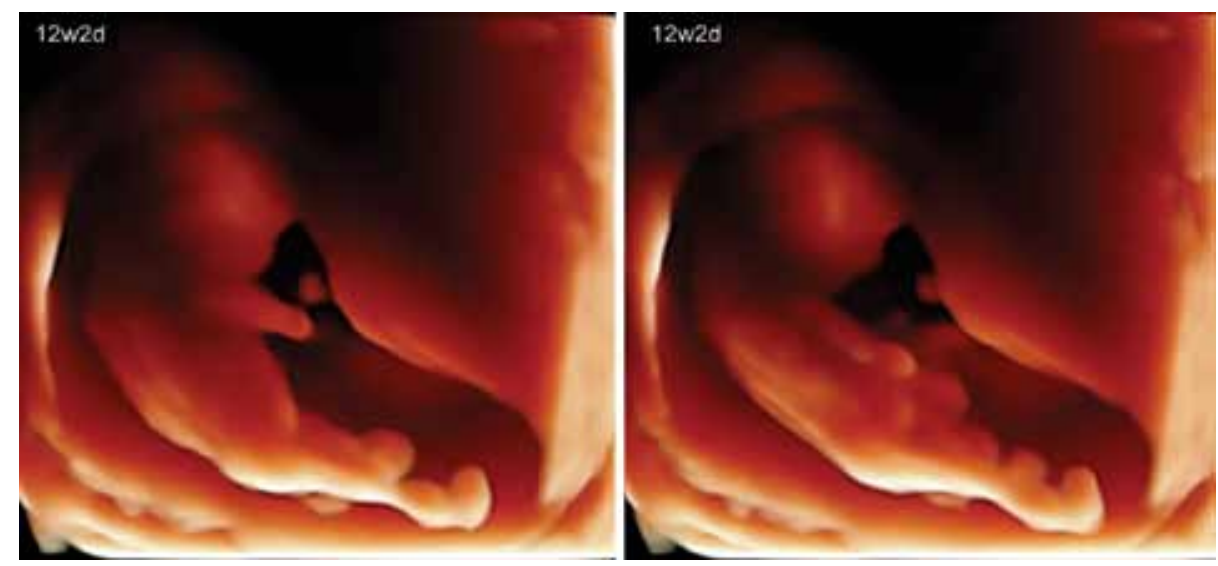

Fig. 4: HDlive images of a fetus at 12 weeks and 2 days of gestation (Courtesy: Reprinted with permission from Hata T, et al) ${ }^{23}$ 


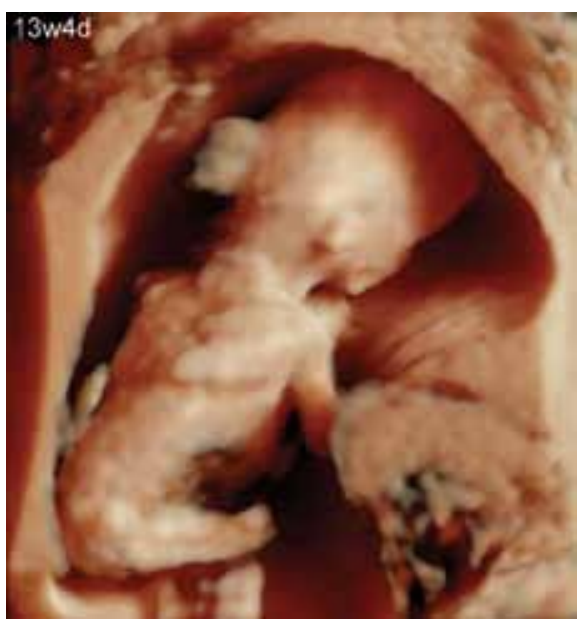

Fig. 5: HDlive image of normal fetuses at 13 weeks and 4 days of gestation

in one gestational sac in monochorionic diamniotic (MD) twins at 8 to 9 weeks of gestation (Figs 8 and 9). Two yolk sacs and the vitelline duct are also depicted (Fig. 9).

HDlive facilitates anatomically realistic visualization of the embryo or fetus, and umbilical cord at 10 to 13 weeks of gestation (Figs 10 to 15). Fetal facial structures such as the eyes, nose, ears, and mouth are noted at 12 to 13 weeks of gestation (Fig. 14). In MD twins, two fetuses in one gestational sac are evident (Figs 10, 11, 13 and 15). In DD twins, each twin fetus in a separate gestational sac with a thin dividing membrane is clearly noted (Figs 12 and 14).
The twin reversed arterial perfusion (TRAP) sequence, also known as fetus acardius, occurs in $0.3 \%$ of monozygotic twin gestations, culminating in a frequency of about 1 per 35,000 deliveries. ${ }^{24,25}$ HDlive provides anatomically realistic images for TRAP sequence diagnosis (Fig. 16). ${ }^{26}$

\section{TWIN FETAL DEVELOPMENT IN THE SECOND TRIMESTER}

Fetal anatomical structures can be identified in the second trimester of pregnancy (Figs 17 to 22). The spatial relationships between twin fetuses can also be clearly noted. In utero crowding of fetuses increases with advancing gestation (Figs 17 to 20). Realistic facial images of both twins can be noted after 20 weeks of gestation, and facial expressions are also evident (Fig. 22).

\section{INTER-TWIN CONTACT AND INTRA-PAIR STIMULATION}

The first inter-twin contacts assessed by 4D ultrasound appeared at 61 postmenstrual days, and the complexity of inter-twin contacts increased from 84 postmenstrual days. ${ }^{13}$ Sasaki et $\mathrm{al}^{6}$ identified a total of 10 inter-twin contacts (head to head, head to arm, head to trunk, head to leg, arm to arm, arm to trunk, arm to leg, trunk to trunk, trunk
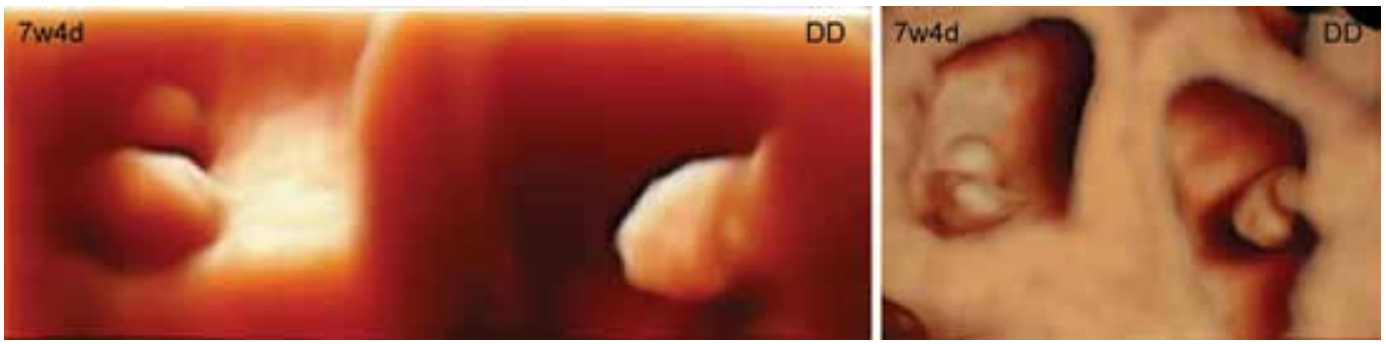

Fig. 6: HDlive images of a dichorionic diamniotic (DD) twin pregnancy at 7 weeks and 4 days of gestation. Each twin fetus in a separate gestational sac with a thick dividing membrane is evident
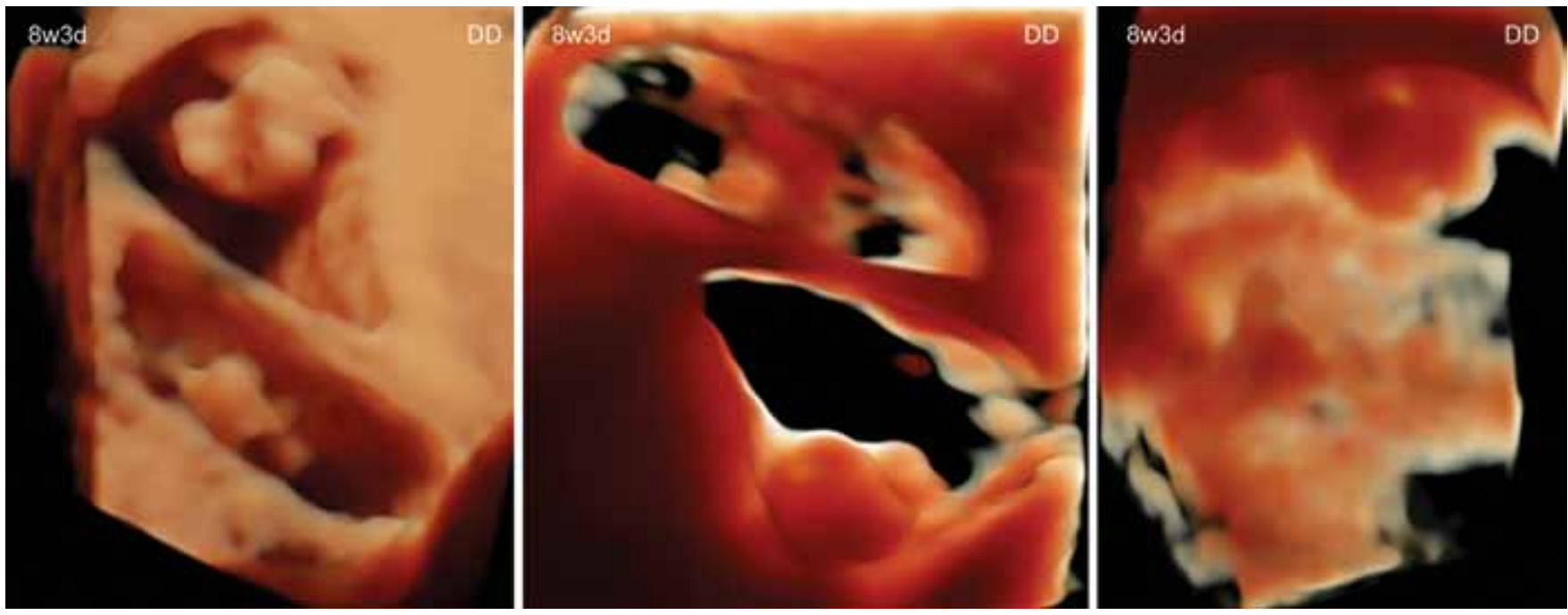

Fig. 7: HDlive images of a dichorionic diamniotic (DD) twin pregnancy at 8 weeks and 3 days of gestation. Each twin fetus in a separate gestational sac with a thick dividing membrane is noted 


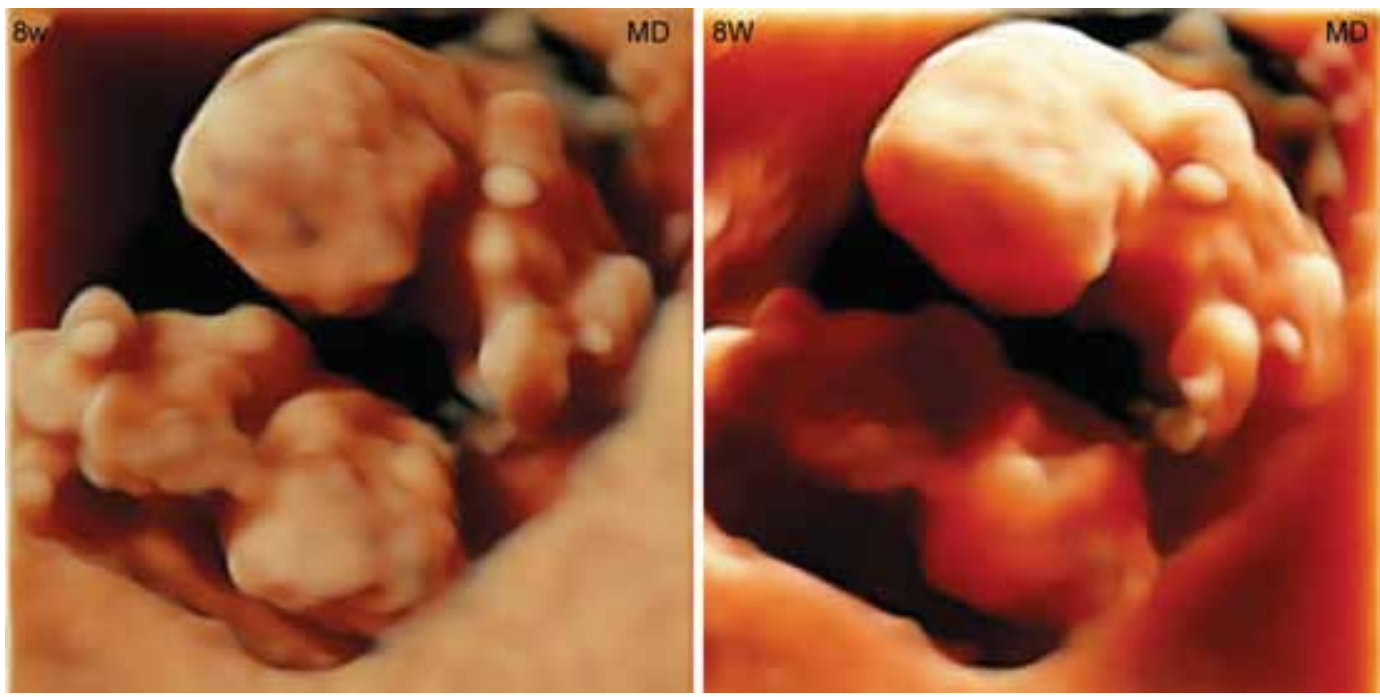

Fig. 8: HDlive images of a monochorionic diamniotic (MD) twin pregnancy at 8 weeks of gestation
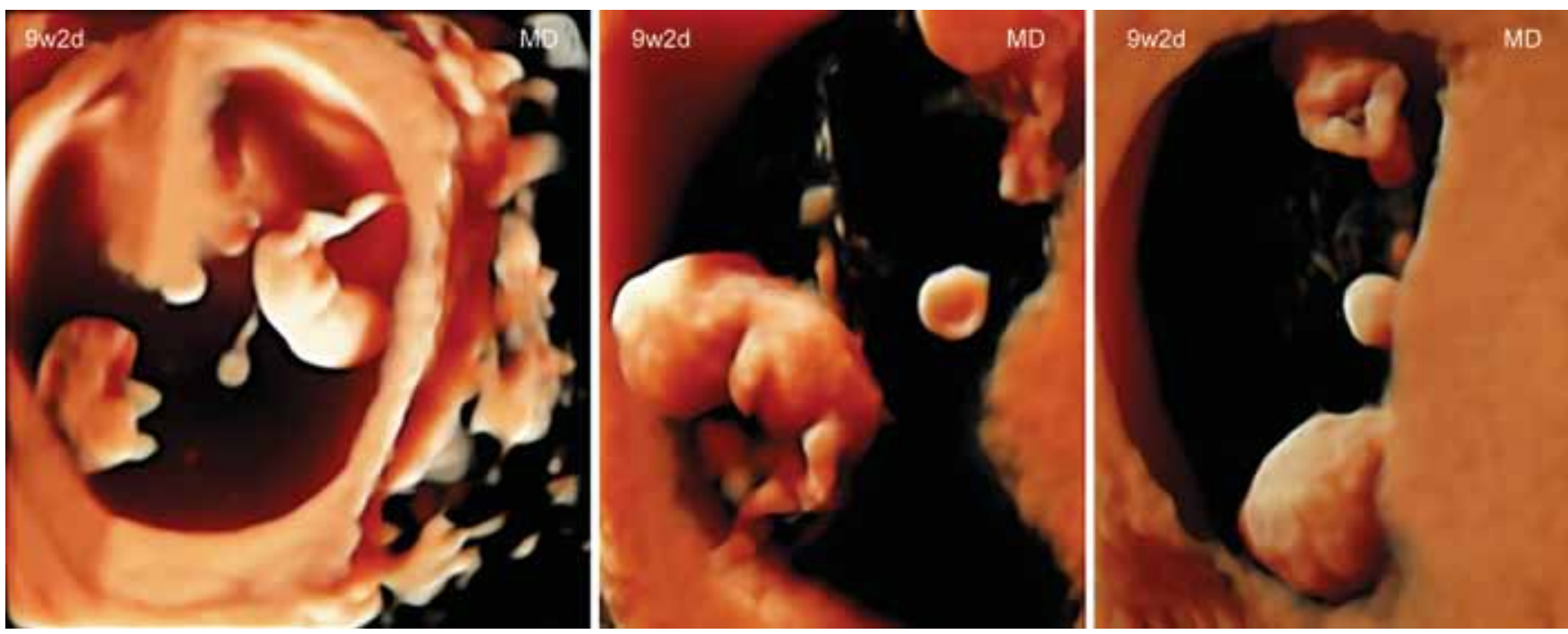

Fig. 9: HDlive images of a monochorionic diamniotic (MD) twin pregnancy at 9 weeks and 2 days of gestation. Two embryos in separate amniotic sacs and two yolk sacs outside the amniotic sac in one gestational sac are noted. The vitelline duct is also depicted
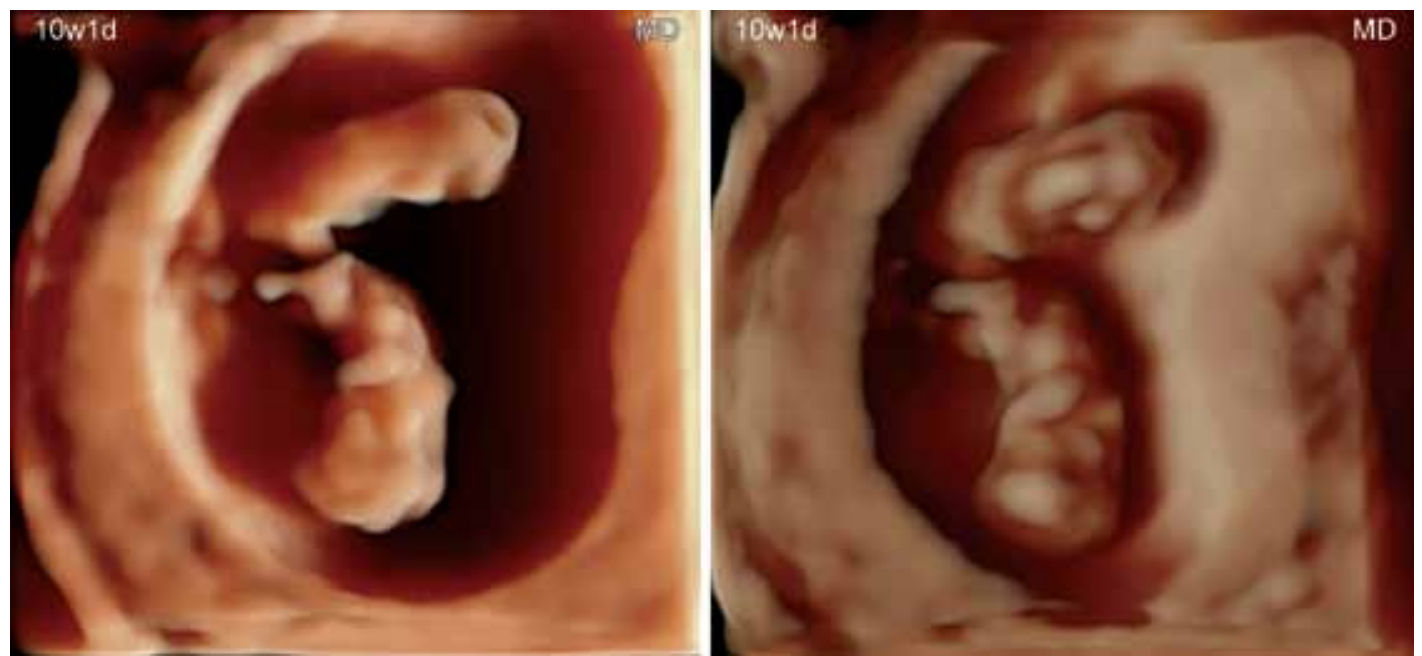

Fig. 10: HDlive images of a monochorionic diamniotic (MD) twin pregnancy at 10 weeks and 1 day of gestation. Two embryos in one gestational sac are evident 


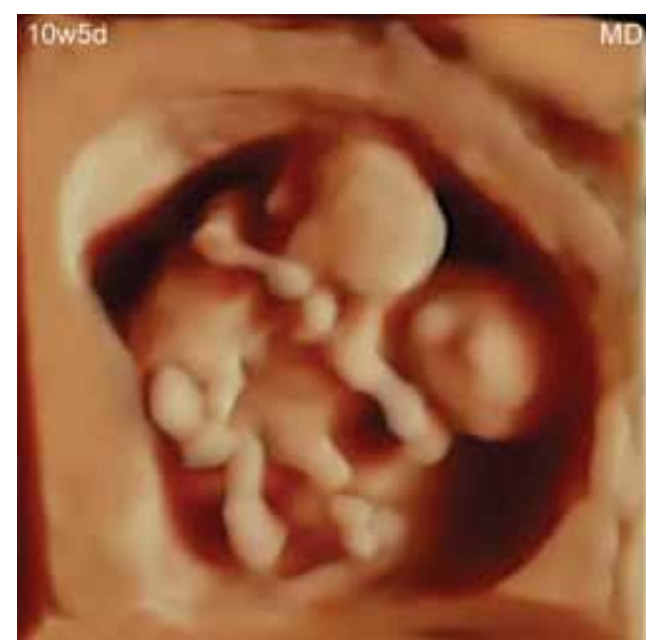

Fig. 11: HDlive image of a monochorionic diamniotic (MD) twin pregnancy at 10 weeks and 5 days of gestation. Two embryos in one gestational sac are clearly shown

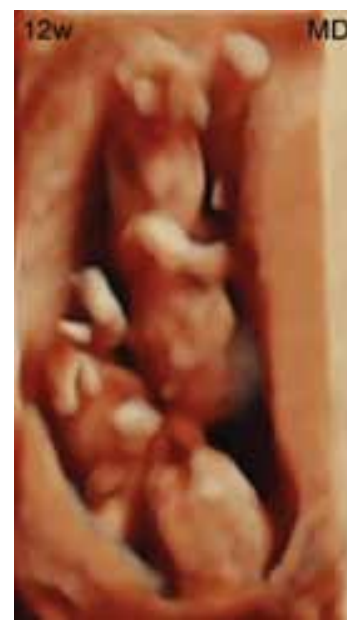

Fig. 13: HDlive image of a monochorionic diamniotic (MD) twin pregnancy at 12 weeks of gestation

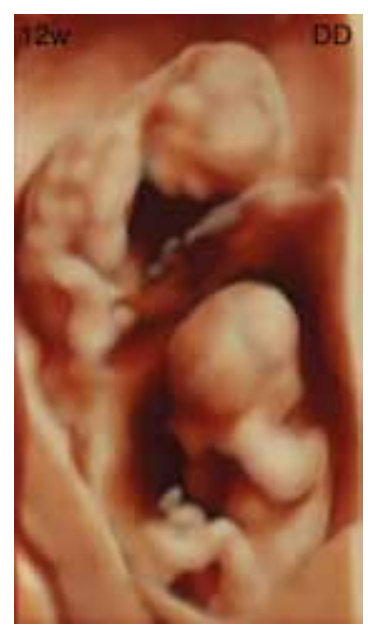

Fig. 14: HDlive image of a dichorionic diamniotic (DD) twin pregnancy at 12 weeks of gestation. Each twin fetus in a separate gestational sac with a very thin dividing membrane is identified

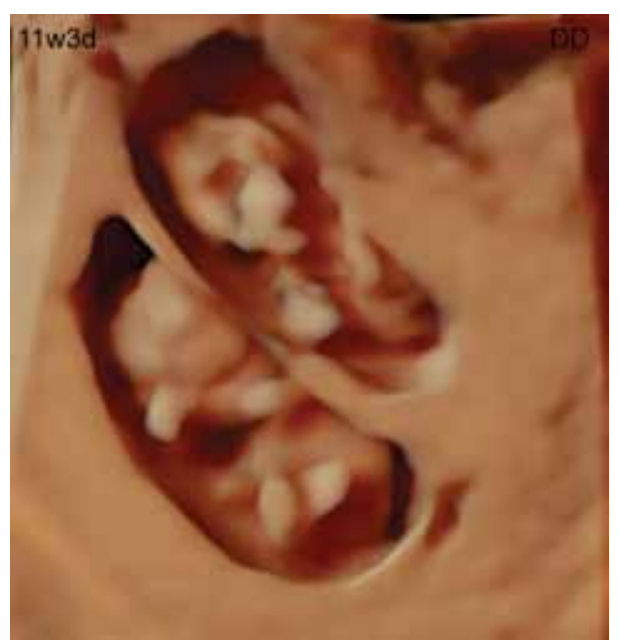

Fig. 12: HDlive image of a dichorionic diamniotic (DD) twin pregnancy at 11 weeks and 3 days of gestation. Each twin fetus in a separate gestational sac with a thin dividing membrane is evident

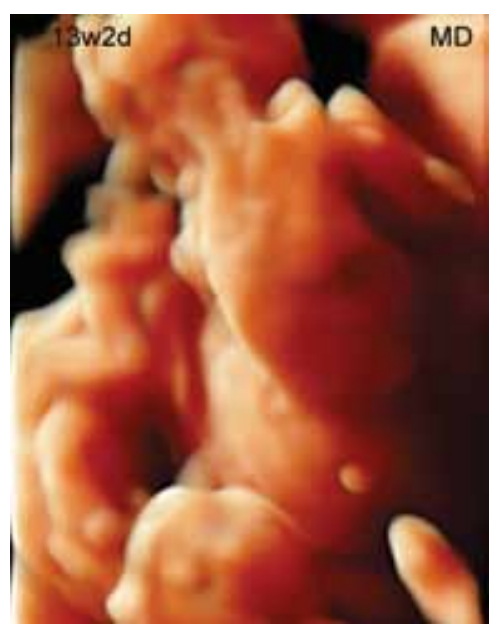

Fig. 15: HDlive image of a monochorionic diamniotic (MD) twin pregnancy at 13 weeks and 2 days of gestation
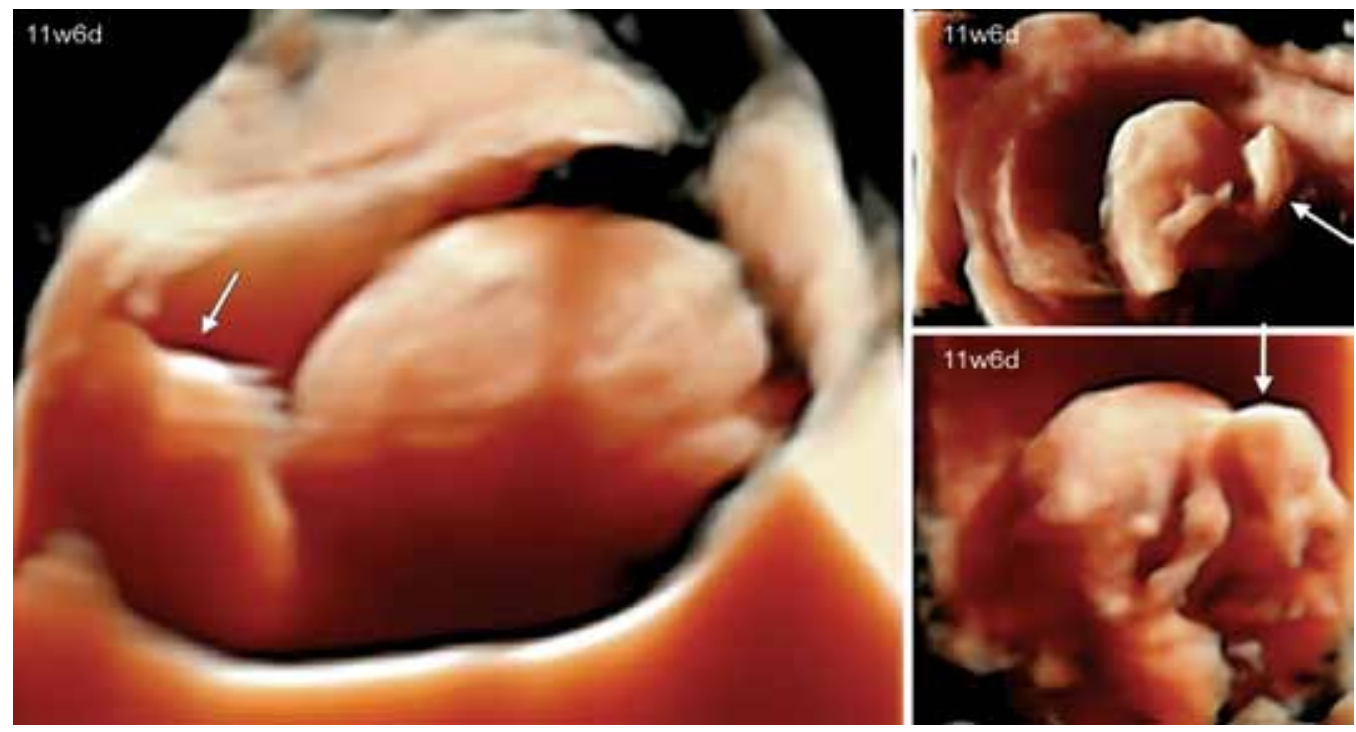

Fig. 16: HDlive images of a twin reversed arterial perfusion sequence at 11 weeks and 6 days of gestation. Anatomically realistic images of the normal sized pump twin and small acardiac twin with acrania and absence of the heart and upper limbs (arrows) are obtained employing HDlive (Courtesy: Reprinted with permission from Hata T, et al) ${ }^{26}$ 


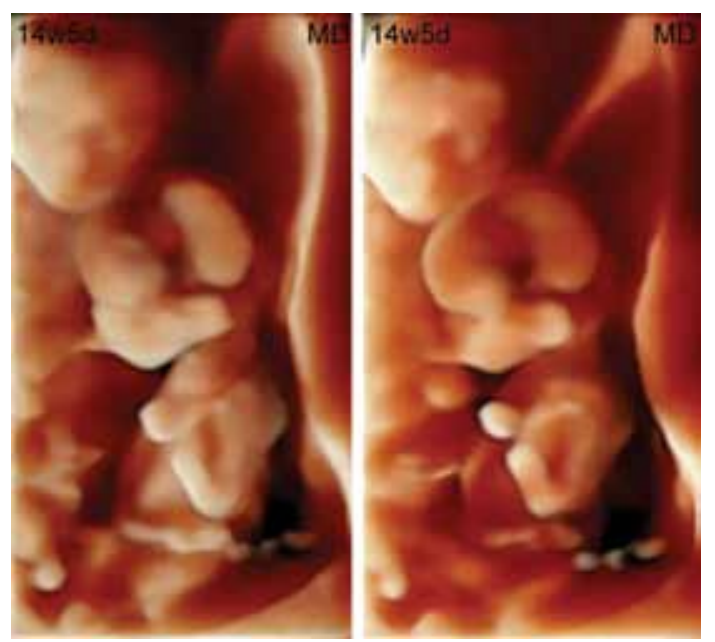

Fig. 17: HDlive images of monochorionic diamniotic (MD) twin fetuses at 14 weeks and 5 days of gestation

to leg and leg to leg) employing $4 \mathrm{D}$ ultrasound late in the first trimester of pregnancy (Figs 23A to J). There was a significant difference in the total number of all contacts between MD and DD twins at 10 to 11 weeks' gestation, and there was also a significant difference in the total number of all contacts between 10 to 11 and 12 to 13 weeks' gestation in DD twins. ${ }^{6}$ There were no significant differences in the frequencies of the 10 types of contact at 10 to 11 or 12 to 13 weeks' gestation in MD pregnancies, and there were also no significant differences in the frequencies of the 10 types at 10 to 11 or 12 to 13 weeks' gestation in DD pregnancies. ${ }^{9}$ The total number of inter-twin contacts in a case of MD twins with acrania of one of the twin fetuses (Figs $24 \mathrm{~A}$ and B) was low compared to those of normal MD twin fetuses at 10-11 and 12-13 weeks' gestation (Fig. 25). ${ }^{27}$ Notably, the frequencies of about half of contacts at 12-13 weeks were low.
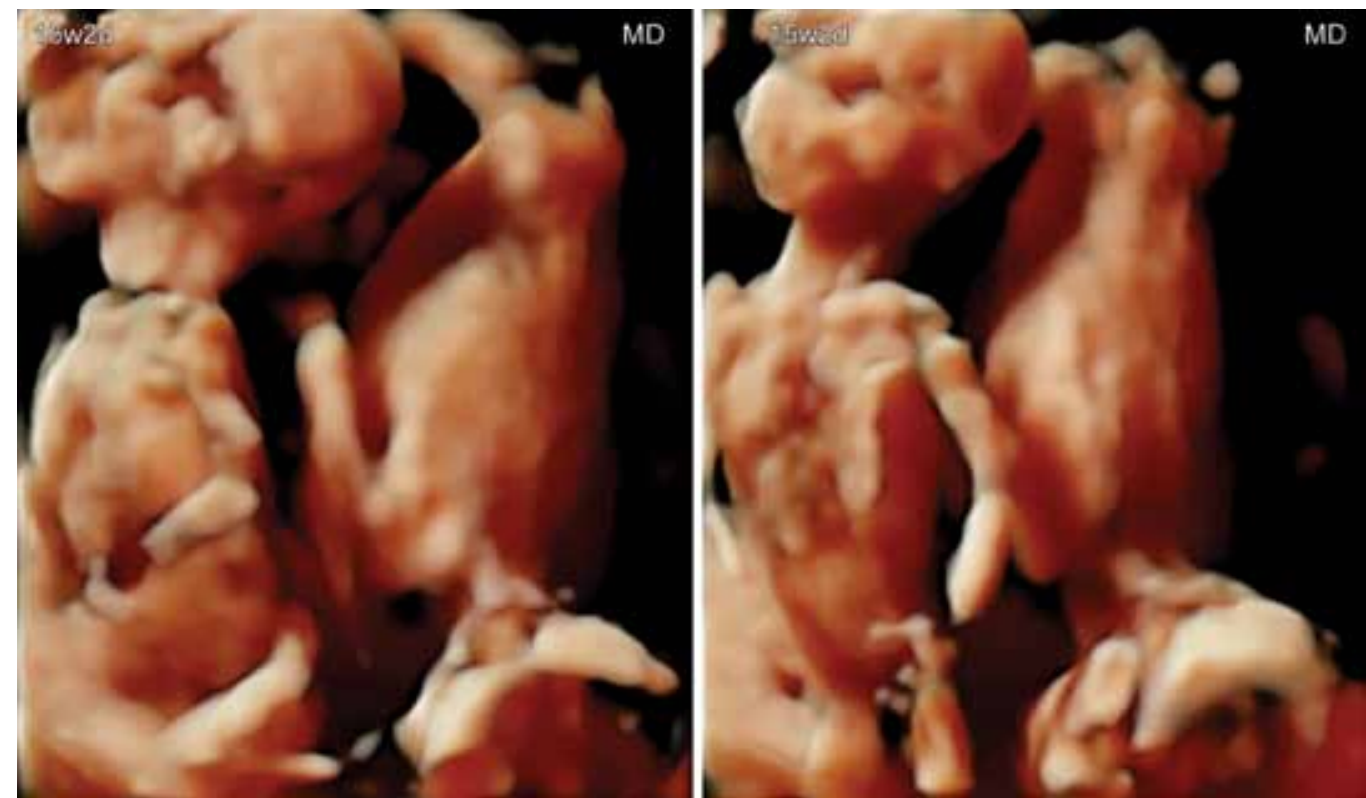

Fig. 18: HDlive images of monochorionic diamniotic (MD) twin fetuses at 15 weeks and 2 days of gestation

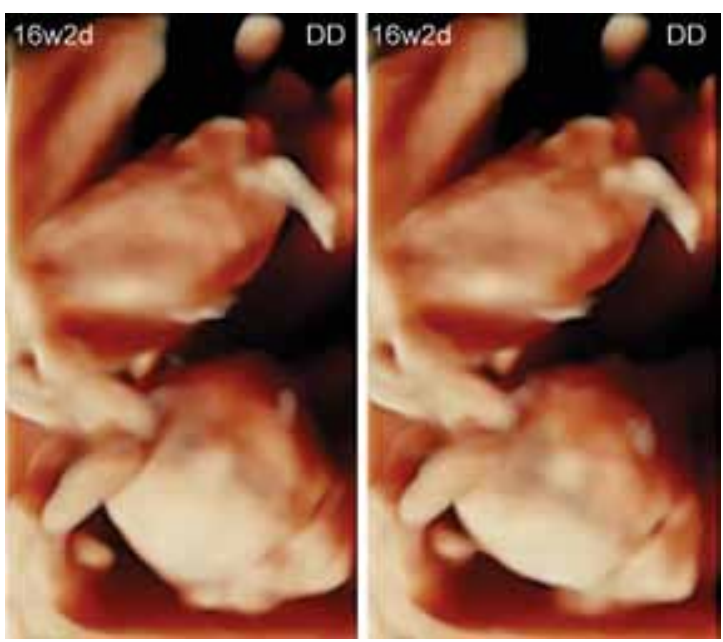

Fig. 19: HDlive images of dichorionic diamniotic (DD) twin fetuses at 16 weeks and 2 days of gestation

Hata et $\mathrm{al}^{4}$ were the first to document reactionary movement in twin fetuses using conventional 3D ultrasound at 25 weeks and 1 day of pregnancy. Several reactionary movements after various types of contact can be recognized using HDlive. Reactionary movements (twins appear to touch each other, and there is a clear reaction by the co-twin) usually occur within a few seconds (Figs 26A and B). No reactionary movement (twins appear to touch each other but there is no clear reaction) is also apparent (Figs 27 and 28). Sometimes, fetal kicking of the face of the co-twin fetus is noted (Figs 29A to D). The median rate of reactionary movements at 12 to 13 weeks' gestation was $33.9 \%{ }^{8}$ The mean timing for touch but no reaction, first reaction and slow body movements was 91 postmenstrual days (13 weeks), that for fast body movements was 92 postmenstrual days (13 weeks and 1 day), and that for more complex contacts was between 93 and 

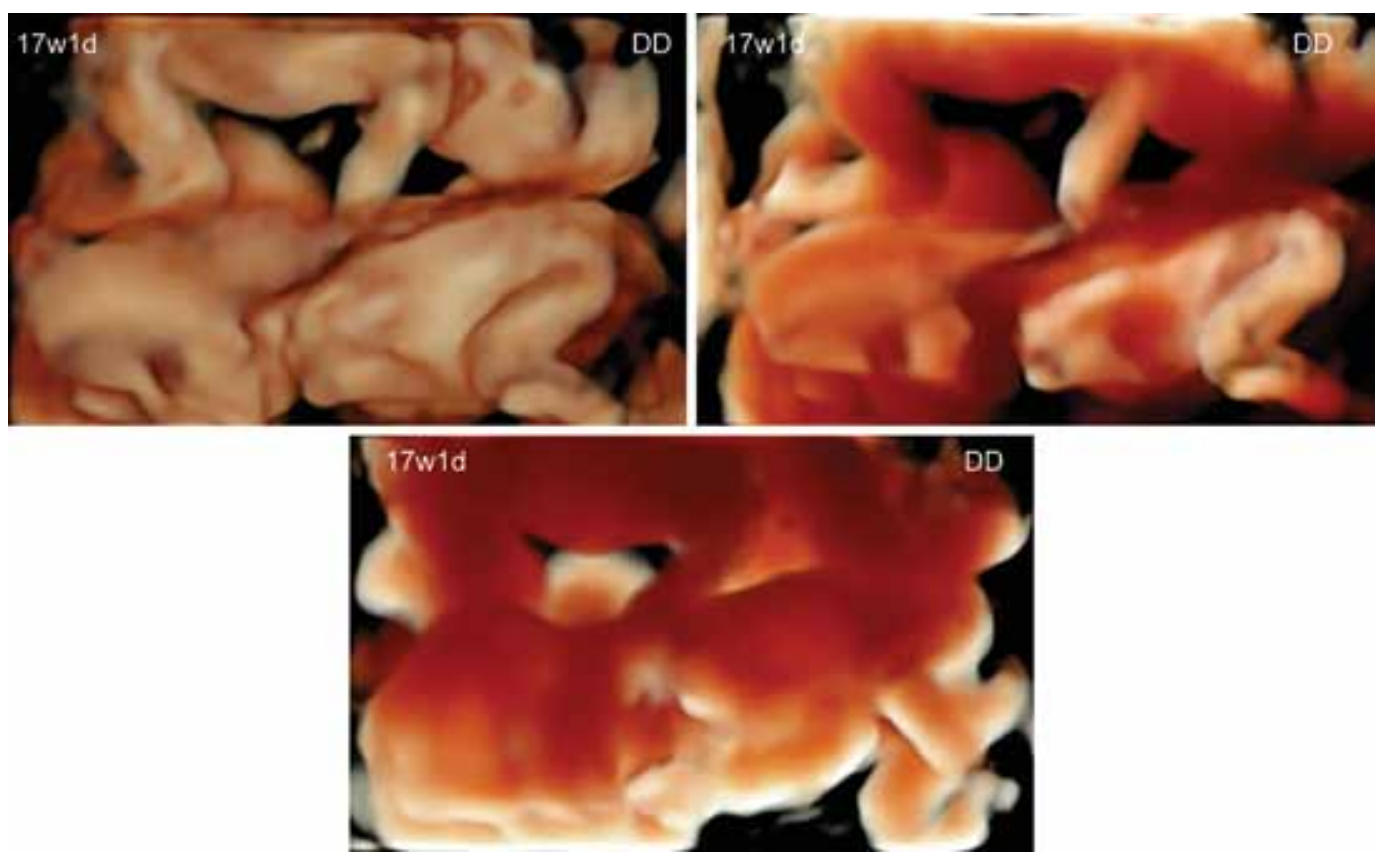

Fig. 20: HDlive images of dichorionic diamniotic (DD) twin fetuses at 17 weeks and 1 day of gestation

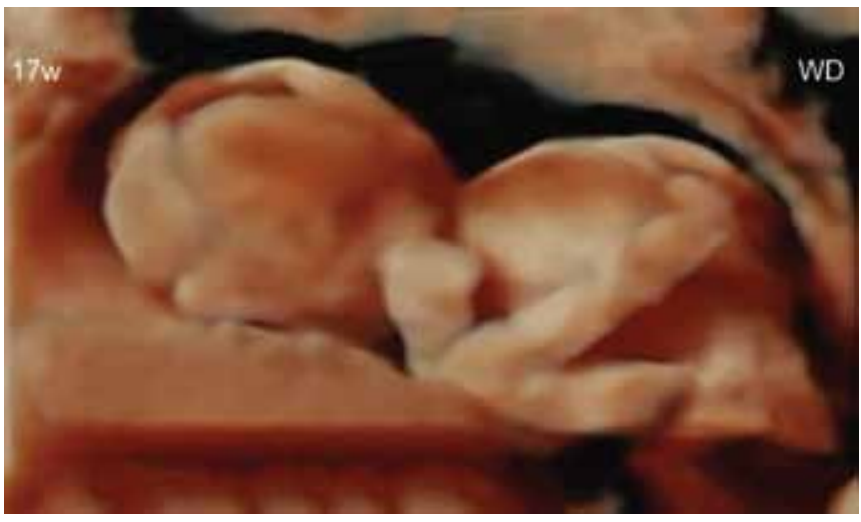

Fig. 21: HDlive image of monochorionic diamniotic (MD) twin fetuses at 17 weeks of gestation. One twin fetus looks like he/she is whispering to the co-twin fetus

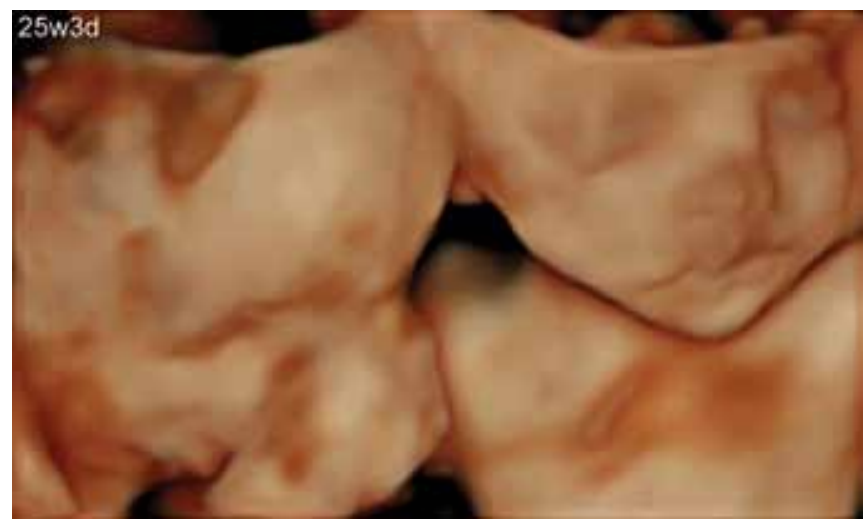

Fig. 22: HDlive image of twin fetuses at 25 weeks and 3 days of gestation. Both twin fetuses appear be disappointed
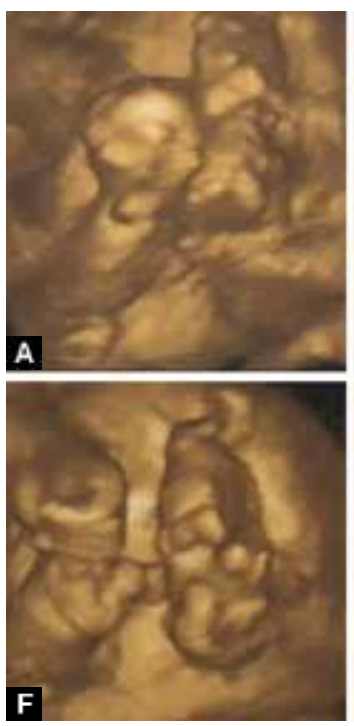

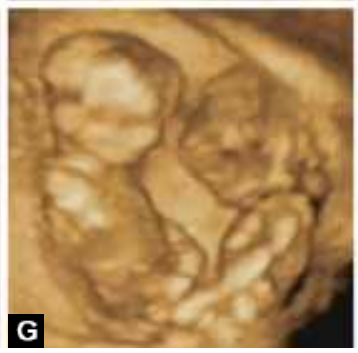

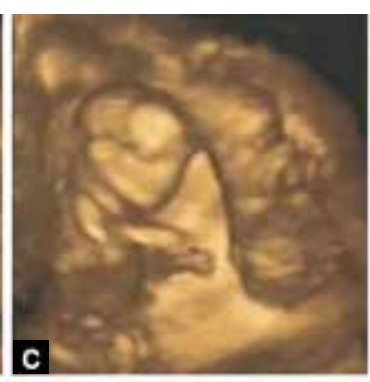

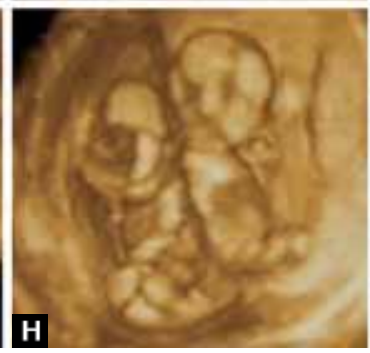

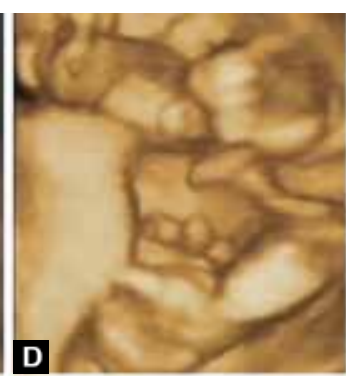
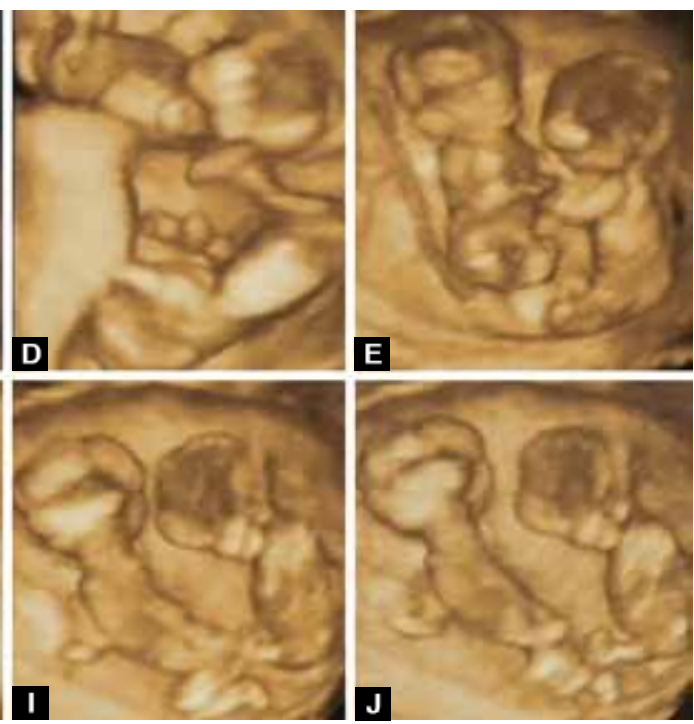

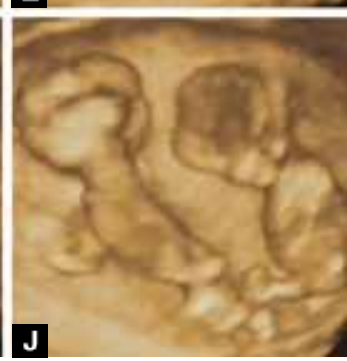

Figs 23A to J: Typical inter-twin contacts shown by four-dimensional ultrasound: (A) Head to head contact, (B) head to arm contact, (C) head to trunk contact, (D) head to leg contact, (E) arm to arm contact, $(F)$ arm to trunk contact, $(G)$ arm to leg contact, (H) trunk to trunk contact, (I) trunk to leg contact, (J) leg to leg contact (Courtesy: Reprinted with permission from Hata T, et al) ${ }^{6}$ 

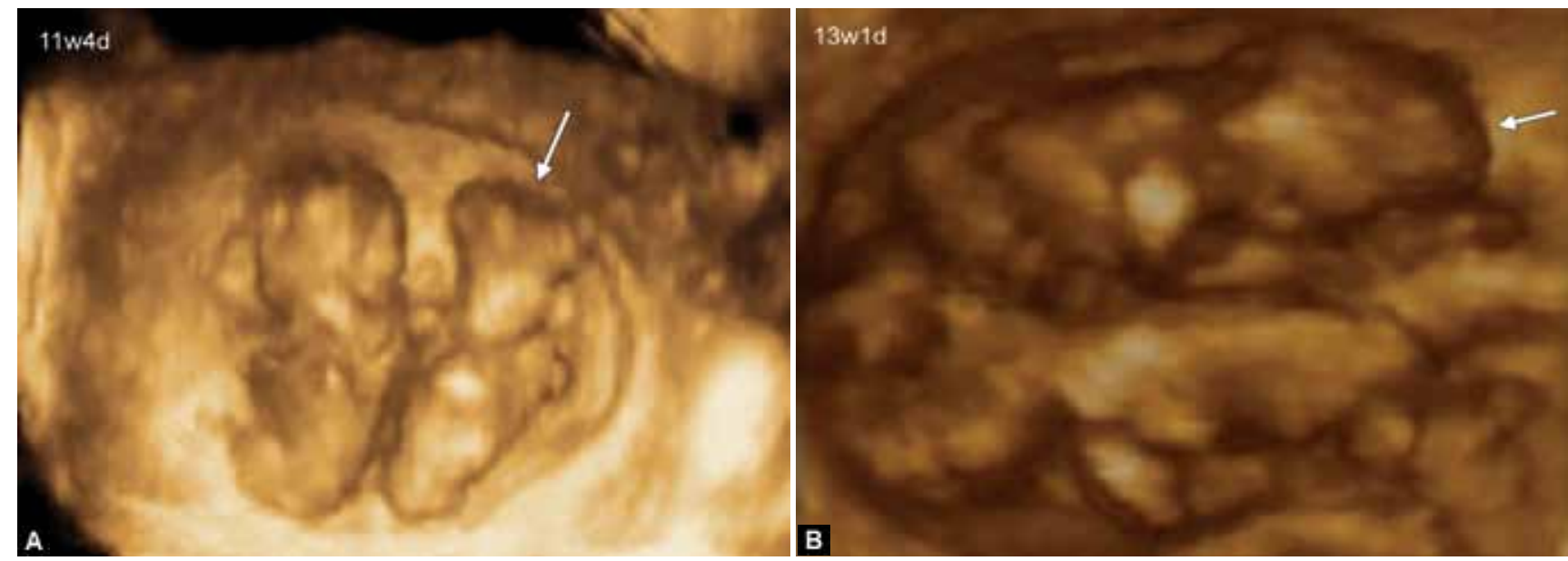

Figs 24A and B: Three-dimensional ultrasound images of a monochorionic diamniotic (MD) twin pregnancy with acrania of one fetus (arrow) at 11 weeks and 4 days (A) and 13 weeks and 1 day (B) of pregnancy, respectively (Courtesy: Reprinted with permission from Hata T, et al) ${ }^{27}$

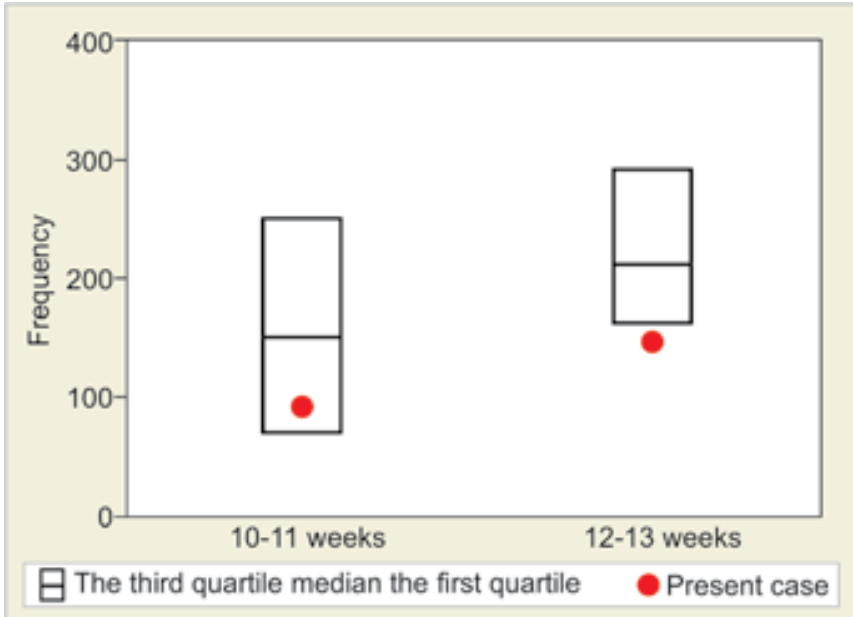

Fig. 25: Total number of all inter-twin contacts in monochorionic diamniotic (MD) twins with acrania of one fetus ( $\bullet$ ). The quartile ranges at 10-11 and 12-13 weeks are adopted from normal MD twins observed in our previous investigation ${ }^{6}$ (Courtesy: Reprinted with permission from Hata $\mathrm{T}$, et al) ${ }^{27}$

95 postmenstrual days (13 weeks and 2 days to 13 weeks and 4 days). ${ }^{13}$ Moreover, diffuse interactions were noticed more often among fetuses between 13 and 16 weeks of gestation..$^{13}$ Interestingly, Castiello et $\mathrm{al}^{1}$ suggested that movements toward the co-twin are not accidental: already starting from the 14th week of gestation, twin fetuses execute movements specifically aimed at the co-twin.

\section{KANET IN TWINS}

The distribution of fetuses from singleton and twin pregnancies belonging to the normal, borderline, and abnormal KANET groups was not found to be significantly different. ${ }^{13}$ However, singletons showed significantly higher KANET scores than twins. Although, twins showed less activity and different behavioral patterns than singletons, a large proportion of their overall motility might be due to inter-twin contacts. ${ }^{13}$
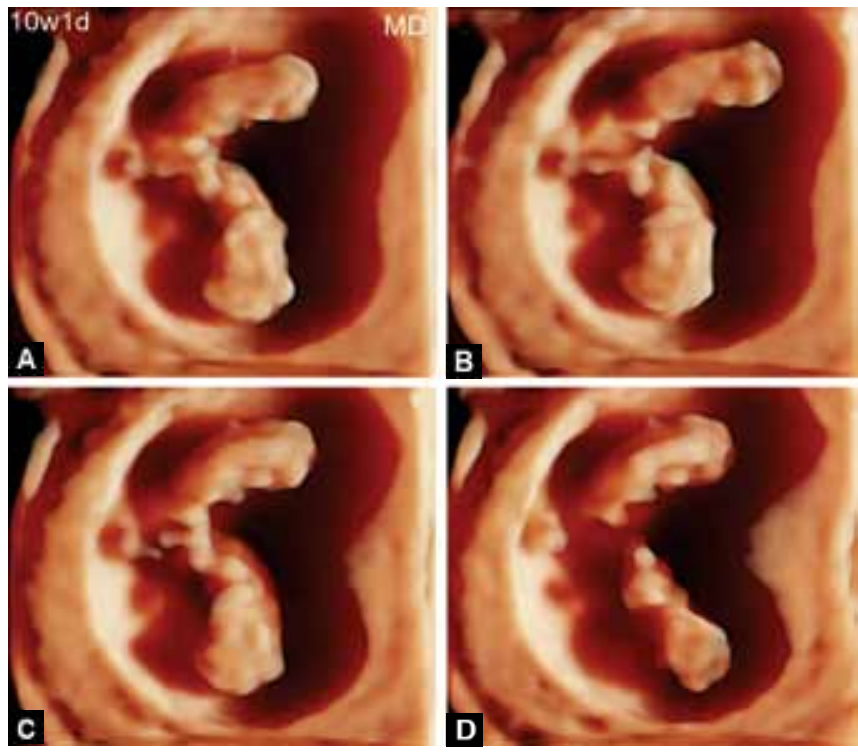

Figs 26A to D: Consecutive HDlive observations of monochorionic diamniotic (MD) twin fetuses at 10 weeks and 1 day of gestation $(A$ to $D)$. Leg-to-leg contact is clearly recognized $(A)$, and there is a clear reaction of the co-twin (second) fetus (upper twin), who shows jumping movement (B), on the contrary, the second twin kicks the first twin's (lower twin) legs (C), and there is a clear reaction of the first twin fetus, who shows jumping movement (D)

\section{PREDICTION OF TWIN TEMPERAMENT}

Degani et $\mathrm{al}^{5}$ studied inter-twin differences in activity at 11 to 14 weeks of gestation, and examined their relationship with infant twins' subsequent temperament. After birth, maternal reports on infants' temperament and the more active twin in each pair were closely associated with prenatal inter-twin differences in activity. Differences in activity in early pregnancy even before the emergence of fetal behavioral patterns were followed by temperamental differences postnatally.

Honemeyer and Kurjak ${ }^{11}$ applied the KANET at different gestational ages to both fetuses in DD twin pregnancy, and compared the results with temperament evaluation of both neonates at 8 weeks after birth. They suggested that 

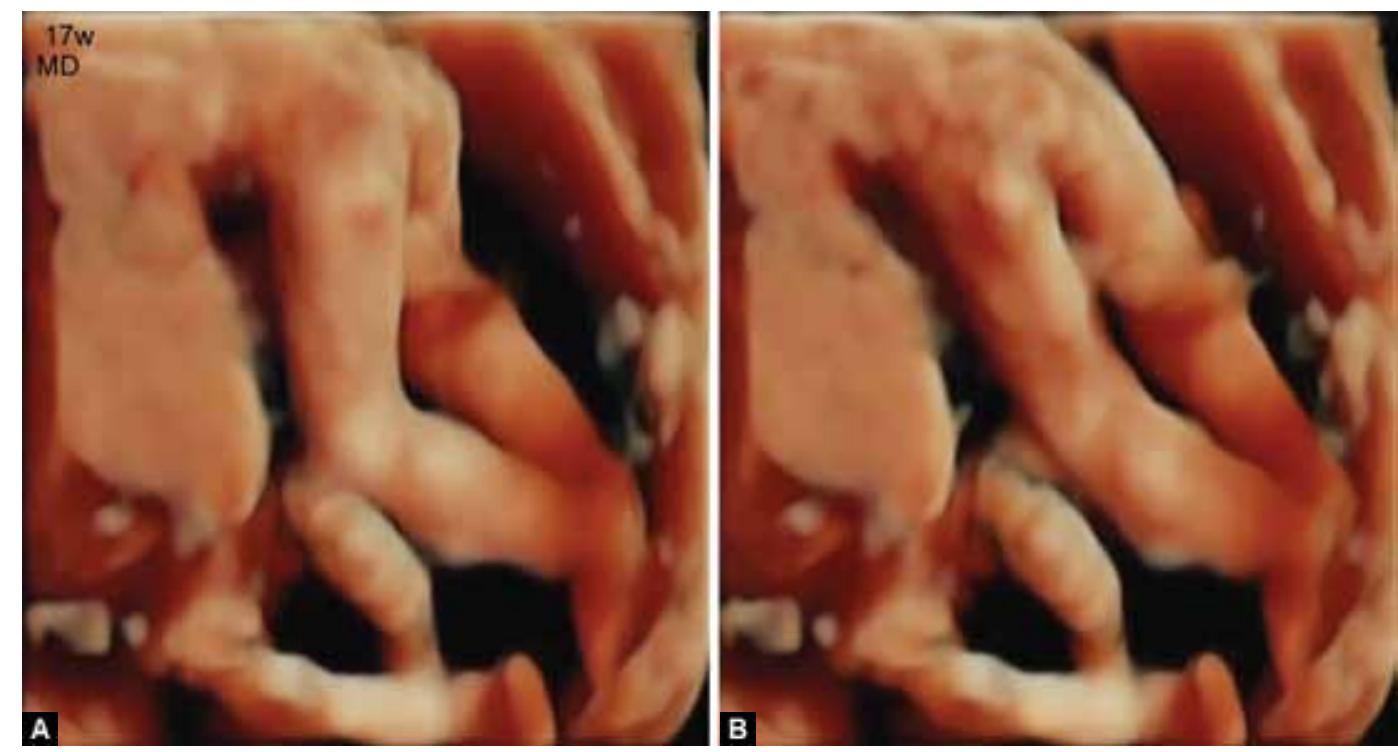

Figs 27A and B: Consecutive HDlive observations of monochorionic diamniotic (MD) twin fetuses at 17 weeks of gestation (A and B). Leg-to-leg contact is clearly noted $(A)$ however, there is no clear reaction of the co-twin fetus (B)
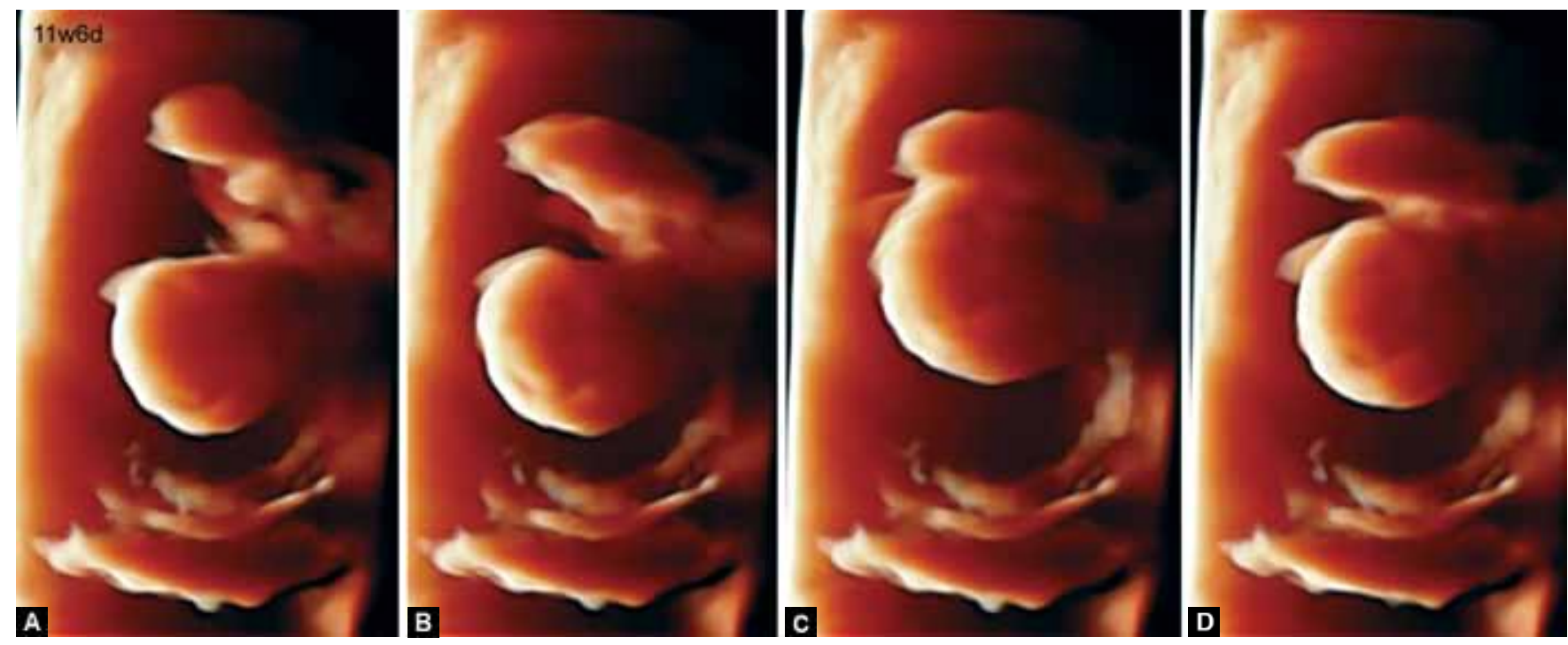

Figs 28A to D: Consecutive HDlive observations of a monochorionic diamniotic (MD) twin pregnancy with acrania of one fetus (upper) at 11 weeks and 6 days of gestation (A to D) Head-to-trunk contact is shown. However, there is no clear reaction of the acranial fetus
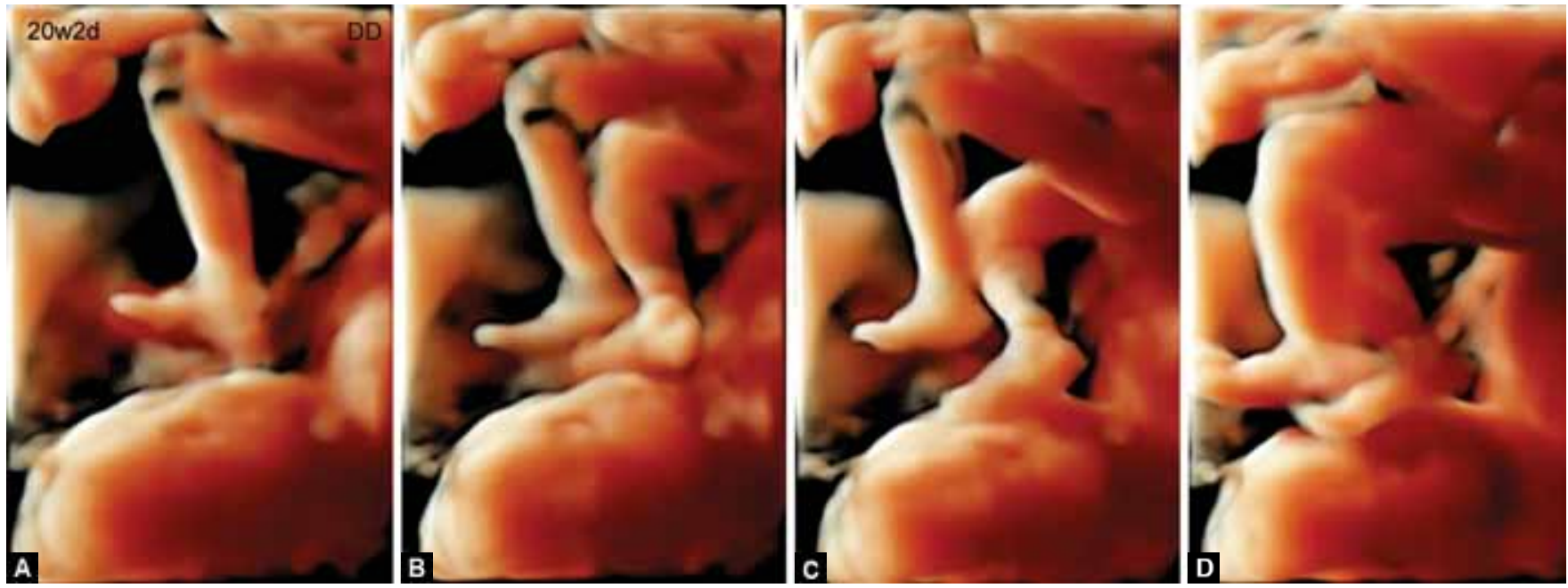

Figs 29A to D: Consecutive HDlive observations of dichorionic diamniotic (DD) twin fetuses at 20 weeks and 2 days of gestation (A to D). Leg-to-head contact (kick in the face) is clearly evident 
development of the temperament is primarily initiated by constitutional factors, and the modulation of these primary settings may be caused by superimposed environmental factors later on.

\section{CONCLUSION}

This review focused on HDlive and 4D ultrasound studies evaluating fetal neurobehavior, inter-twin contact, and intra-pair stimulation in twin pregnancies. HDlive and 4D ultrasound studies of fetal behavior, behaviorrelated phenomena and fetal reflexes in twin pregnancy may provide us with an effective method of understanding the developmental pathway of the fetal brain and central nervous system, and the potentialities of the neurological investigation of twin fetuses. In particular, the use of HDlive facilitates natural, realistic images of both embryos and fetuses in MD and DD pregnancies, with the images being much more detailed compared to those using conventional 3D/4D ultrasound. In all three trimesters of pregnancy, HDlive generates more realistic images to assess twin pregnancy; thus, it may be a very important future modality for twin research and the antenatal evaluation of abnormal twin fetuses in utero.

\section{ACKNOWLEDGMENTS}

The work reported in this paper was supported by a Grant-in-Aid for Scientific Research on Innovative Areas 'Constructive Developmental Science' (No. 24119004), and a Research Grant (No. 25462561) from The Ministry of Education, Culture, Sports, Science and Technology, Japan.

\section{REFERENCES}

1. Castiello U, Becchio C, Zoia S, Nelini C, Sartori L, Blason L, D'Ottavio G, Bulgheroni M, Gallese V. Wired to be social: the ontogeny of human interaction. PLoS ONE 2010;5(10):e13199.

2. Arabin B, Bos R, Rijlaarsdam R, Mohnhaupt A, van Eyck J. The onset of inter-human contacts: longitudinal ultrasound observations in early twin pregnancies. Ultrasound Obstet Gynecol 1996;8(3):166-173.

3. Piontelli A, Bocconi L, Kustermann A, Tassis B,ZoppiniC, Nicolini U. Patterns of evoked behaviour in twin pregnancies during the first 22 weeks of gestation. Early Hum Dev 1997;50(1):39-45.

4. Hata T, Aoki S, Miyazaki K, Iwanari O, Sawada K, Tagashira T. Three-dimensional ultrasonographic visualization of multiple pregnancy. Gynecol Obstet Invest 1998;46(1):26-30.

5. Degani S, Leibovitz Z, Shapiro I, Ohel G. Twins' temperament: early prenatal sonographic assessment and postnatal correlation. J Perinatol 2009;29(5):337-342.

6. Sasaki M, Yanagihara T, Naitoh N, Hata T. Four-dimensional sonographic assessment of inter-twin contact late in the first trimester. Int J Gynecol Obstet 2010;108(2):104-107.

7. Hata T, Kanenishi K, Tanaka H, Marumo G, Sasaki M. Fourdimensional ultrasounds evaluation of fetal neurobehavioral development. Donald School J Ultrasound Obstet Gynecol 2010;4(3):233-248.

8. Hata T, Kanenishi K, Sasaki M, Yanagihara T. Fetal reflex movement in twin pregnancies late in the first trimester: 4-D sonographic study. Ultrasound Med Biol 2011;37(11):1948-1951.
9. Hata T, Sasaki M, Yanagihara T. Difference in the frequency of types of inter-twin contact at 10-13 weeks' gestation: preliminary four-dimensional sonographic study. J Matern Fetal Neonatal Med 2012;25(3):226-230.

10. Hata T, Sato M, Kanenishi K, Hanaoka U, Tanaka H. 4D sonography in assessment of fetal neurobehavior. Donald School J Ultrasound Obstet Gynecol 2012;6(2):121-131.

11. Honemeyer $U, K u r j a k A$. Prenatal beginnings of temperament formation - Myth or reality? Case study of a twin pregnancy. Donald School J Ultrasound Obstet Gynecol 2012;6(2):148-153.

12. Prats P, Serra B, Fournier S, Baulies S, Andonotopo W, Kurjak A. 4D sonographic assessment of intertwine contacts. Donald School J Ultrasound Obstet Gynecol 2012;6(2):154-159.

13. Kurjak A, Talic A, Stanojevic M, Honemeyer U, Serra B, Prats P, Di Renzo GC. The study of fetal neurobehavior in twins in all three trimesters of pregnancy. J Matern Fetal Neonatal Med 2013;26(12):1186-1195.

14. Kagan KO, Pintoffl K, Hoopmann M. First-trimester ultrasound images using HDlive. Ultrasound Obstet Gynecol 2011;38(5):607.

15. Merz E. Surface reconstruction of a fetus $(28+2 \mathrm{GW})$ using HDlive technology. Ultraschall Med 2012;33(3):211-212.

16. Hata T, Hanaoka U, Tenkumo C, Sato M, Tanaka H, Ishimura $\mathrm{M}$. Three- and four-dimensional HDlive rendering images of normal and abnormal fetuses: pictorial essay. Arch Gynecol Obstet 2012;286(6):1431-1435.

17. Hata T. HDlive rendering image at 6 weeks of gestation. J Med Ultrasonics 2013;40(4):495-496.

18. Hata T, Hanaoka U, Mashima M, Ishimura M, Marumo G, Kanenishi K. Four-dimensional HDlive rendering image of fetal facial expression: a pictorial essay. J Med Ultrasonics 2013;40(4):437-441.

19. Hata T, Hanaoka U, Tenkumo C, Ito M, Uketa E, Mori N, Kanenishi K, Tanaka H, Ishimura M. Three-dimensional HDlive rendering image of cystic hygroma. J Med Ultrasonics 2013;40(3):297-299.

20. Hata T, Uketa E, Tenkumo C, Hanaoka U, Kanenishi K, Tanaka $\mathrm{H}$. Three- and four-dimensional HDlive rendering image of fetal acrania/exencephaly in early pregnancy. J Med Ultrasonics 2013;40(3):271-273.

21. Hata T, Hanaoka U, Mashima M. HDlive rendering image of cyclopia and a proboscis in a fetus with normal chromosomes at 32 weeks of gestation. J Med Ultrasonics 2014;41(1):109-110.

22. Hanaoka U, Tanaka H, Koyano K, Uematsu R, Kanenishi K, Hata T. HDlive imaging of the fetal face in fetuses with autosomal trisomies. J Med Ultrasonics 2014;41(3):339-342.

23. Hata T, Kanenishi K, Hanaoka U, Uematsu R, Marumo G, Tanaka H. HDlive study of fetal development and behavior. Donald School J Ultrasound Obstet Gynecol 2014;8(3):250-265.

24. Gillim DL, Hendricks CH. Holocardius: review of the literature and case report. Obstet Gynecol 1953;2(6):647-653.

25. Napolitani FH, Schreiber I. The acardiac monster: a review of the world literature and presentation of two cases. Am J Obstet Gynecol 1960;80(3):582-589.

26. Tenkumo C, Tanaka H, Ito M, Uketa E, Mori N, Hanaoka U, Kanenishi K, Ando M, Hata T. Three-dimensional HDlive rendering images of the TRAP sequence in the first trimester: reverse end-diastolic umbilical artery velocity in a pump twin with an adverse pregnancy outcome. J Med Ultrasonics 2012;40(3):293-296.

27. Hata T, Kanenishi K, Hanaoka U, Sasaki M, Yanagihara T. Inter-twin contact in a case of monochorionic diamniotic twins with acrania of one twin fetus at 10-13 weeks' gestation. J Med Ultrasonics 2012;39(1):45-47. 